\title{
Profile of Executive and Memory Function Associated with Amphetamine and Opiate Dependence
}

\author{
Karen D Ersche ${ }^{1,2}$, Luke Clark ${ }^{2,3}$, Mervyn London4, Trevor W Robbins ${ }^{2,3}$ and Barbara J Sahakian*,1,2 \\ 'Department of Psychiatry, School of Clinical Medicine, University of Cambridge, Addenbrooke's Hospital, Cambridge, UK; ${ }^{2}$ Behavioural and \\ Clinical Neuroscience Institute, University of Cambridge, Cambridge, UK; ${ }^{3}$ Department of Experimental Psychology, University of Cambridge, \\ Cambridge, UK; ${ }^{4}$ Brookfields Hospital, Cambridge Drug \& Alcohol Service, Cambridge, UK
}

\begin{abstract}
Cognitive function was assessed in chronic drug users on neurocognitive measures of executive and memory function. Current amphetamine users were contrasted with current opiate users, and these two groups were compared with former users of these substances (abstinent for at least one year). Four groups of participants were recruited: amphetamine-dependent individuals, opiatedependent individuals, former users of amphetamines, and/or opiates and healthy non-drug taking controls. Participants were administered the Tower of London (TOL) planning task and the 3D-IDED attentional set-shifting task to assess executive function, and Paired Associates Learning and Delayed Pattern Recognition Memory tasks to assess visual memory function. The three groups of substance users showed significant impairments on TOL planning, Pattern Recognition Memory and Paired Associates Learning. Current amphetamine users displayed a greater degree of impairment than current opiate users. Consistent with previous research showing that healthy men are performing better on visuo-spatial tests than women, our male controls remembered significantly more paired associates than their female counterparts. This relationship was reversed in drug users. While performance of female drug users was normal, male drug users showed significant impairment compared to both their female counterparts and male controls. There was no difference in performance between current and former drug users. Neither years of drug abuse nor years of drug abstinence were associated with performance. Chronic drug users display pronounced neuropsychological impairment in the domains of executive and memory function. Impairment persists after several years of drug abstinence and may reflect neuropathology in frontal and temporal cortices.
\end{abstract}

Neuropsychopharmacology (2006) 3I, I036-1047. doi:I0. I038/s..npp. I 300889; published online 14 September 2005

Keywords: amphetamines; opiates; substance abuse; abstinence; impulsivity; neuropsychological assessment

\section{INTRODUCTION}

Chronic use of psychoactive substances is associated with widespread deficits in neuropsychological function (Rogers and Robbins, 2001, 2003; Verdejo-Garcia et al, 2004). Deficits are pronounced in the executive domain including decision-making (Bechara et al, 2001, 2002; Bechara and Damasio, 2002; Grant et al, 2000), response inhibition (Fillmore, 2003; Kaufman et al, 2003; Hester and Garavan, 2004), planning (Ornstein et al, 2000), and working memory (Verdejo-Garcia et al, 2005; Mintzer and Stitzer, 2002). These deficits may be associated with prefrontal cortex

* Correspondence: Professor BJ Sahakian, Department of Psychiatry, School of Clinical Medicine, University of Cambridge, Box 189 , Addenbrooke's Hospital, Cambridge, Cambridgeshire CB2 2QQ, UK, Tel: + 441223331209 , Fax: + 441223336968 ,

E-mail: ke220@cam.ac.uk

Received 10 May 2005; revised I August 2005; accepted 2 August 2005

Online publication: 4 August 2005 at http://www.acnp.org/citations/ Npp0804050503/3/default.pdf dysfunction, and their extent and nature is likely to depend on the substance of abuse.

The present study compares executive function and memory in current users of amphetamines and opiates, both widely used substances (United Nations Office on Drugs and Crime, 2003) with distinctly different pharmacological actions. The acute pharmacological effects of amphetamines are to increase central monoamine neurotransmission by interaction with processes of transmitter release, uptake, and metabolism (for a review, see Seiden et al, 1993). Opiates, in contrast, exert their action mainly through $\mu$-opioid receptors, indirectly increasing dopamine (DA), but decreasing noradrenaline (NA) levels (De Vries and Shippenberg, 2002; Maldonado, 1997). The chronic effects of prolonged substance abuse may differ between users of amphetamines and opiates. Examination of postmortem brains indicates qualitatively more severe neuropathology in amphetamine users compared to opiate users (Kish et al, 2001; Wilson et al, 1996). While in opiate users, non-specific ventricular and cortical volume loss has been reported (Danos et al, 1998; Pezawas et al, 1998), structural 
abnormalities identified in brains of psychostimulant users (ie cocaine, methamphetamine) are more specific, encompassing particularly prefrontal and medial temporal lobe areas (Fein et al, 2002; Matochik et al, 2003; Thompson et $a l, 2004)$. Furthermore, alterations in brain function in psychostimulant users have shown direct associations with impaired working memory performance (Goldstein et al, 2004; Newton et al, 2004).

Despite growing evidence of the different neuropathology associated with chronic amphetamine and opiate use, respectively, neuropsychological research directly comparing cognitive performance in amphetamine and opiate users is still sparse. There is evidence that chronic amphetamine users display deficits in decision-making which are not evident in opiate users (Rogers et al, 1999b). Ornstein et al (2000) also found qualitative differences in attentional setshifting between these two substance user groups, while on other measures of executive functions the two groups were equally impaired. The aim of the present study was to further investigate impairment of executive function subserved by dorsolateral prefrontal networks. We based our investigation on the Ornstein et al (2000) study, using a larger sample together with more sensitive task versions of visuo-spatial planning, attentional set-shifting, and pattern recognition. We also included a paired associate learning (PAL) task, which has shown sensitivity to mesiotemporalfrontal networks (Bullmore et al, 2003; Gould et al, 2003; Owen et al, 1995b; Sahakian et al, 1988). In addition, a group of former substance users was introduced to control for the direct pharmacological actions in the current drug user groups, and to assess the reversibility of any effect with prolonged abstinence. Urine screens prior to testing were carried out to confirm drug intake or abstinence. Since mood disorders are common in chronic substance users (Grant et al, 2004), we chose not to exclude participants who scored highly on the Beck Depression Inventory (BDI), but decided instead to statistically control for mood. We hypothesized that drug users compared to controls would show impairment on all neurocognitive tests administered, but chronic use of amphetamines would produce greater neurocognitive impairment than the use of opiates.

\section{METHODS}

\section{Participants}

The study received ethical approval from local research committees in Cambridge, Huntingdon, Fenland-Peterborough, and West-Suffolk. Substance users were recruited through local drug dependency units, charities providing services for drug users, and by word of mouth. Ex-drug users were recruited via Narcotics Anonymous and controls by advertisements in the local area. Prior to testing, all participants gave written informed consent. They underwent a screening process by a post-graduate psychologist using locally developed instruments concerning the history of drug use and diagnosis for substance dependence according to the DSM-IV (American Psychiatric Association, 1994), general health and demographic characteristics. Urine samples were analyzed for the following drugs: morphine, methadone, amphetamine, cocaine, and benzodiazepines using the SureStep Drug Screen Test (Euromed
Limited, London, UK). All participants were compensated for their time. Criterion for inclusion for substance users was a minimum of 3 years dependence on either amphetamines or the opiates. Ex-drug users met criteria for past dependence on either opiates or amphetamines, but had been abstinent from all substances of abuse (except nicotine) for at least one year. Control participants were only included in the study if they had no drug-taking history. Exclusion criteria, which applied for all groups, were the following: color-blindness, a co-morbid psychiatric illness, a history of a head injury, a history of an overdose requiring resuscitation and overnight hospitalization. Dependence on another drug apart from the one falling under the inclusion criterion or nicotine led to exclusion from the study. Participants reporting a regular consumption of alcoholic beverage exceeding $21 \mathrm{U} /$ week for men and $14 \mathrm{U} /$ week for woman were also excluded from the study. Table 1 displays the drug-taking habits of other substances apart from their drug of choice, by current substance users.

The amphetamine-dependent group was composed of 25 chronic amphetamine users. Seven amphetamine users were prescribed $\mathrm{D}$-amphetamine (Dexedrine ${ }^{\circledR}$ ) from a Consultant Psychiatrist (mean \pm standard deviation (SD) dose: $36 \pm 21.9 \mathrm{mg}$, dose range: $15-70 \mathrm{mg}$ ), a substitute treatment for amphetamine dependence in accordance with the UK Department of Health guidelines (UK Department of Health, 1999). One participant who received Dexedrine ${ }^{\circledR}$ on prescription was also prescribed benzodiazepines. Amphetamine users without a prescription consumed street amphetamine daily. In all, $88 \%$ of amphetamine users were tobacco smokers (mean \pm SD $12 \pm 8.1$ cigarettes/day). One street amphetamine user was HIV positive. Out of 25 urine screens, 23 tested positive for amphetamine (additional substances: six morphine, two benzodiazepines, three cocaine). One sample, which was negative for amphetamine, was positive for cocaine. The other negative sample was provided by a chronic amphetamine user, who had consumed a very large amount of non-alcoholic liquids, and therefore was included in the study. The opiate dependency group was formed of 42 chronic opiate users. Twenty-seven opiate users were on a methadone prescription (mean \pm SD dose: $45.2 \pm 17.9 \mathrm{mg}$, dose range: 20-80 mg). Two methadone-maintained participants also received benzodiazepines on prescription. One opiate user was on a prescription of $4 \mathrm{mg}$ buprenorphine (Subutex ${ }^{\circledR}$ ), another one received $4 \times 60 \mathrm{mg}$ dihydrocodeine (Sono$\left.\operatorname{dor}^{\circledR}\right)$. A further opiate user had a prescription for $200 \mathrm{mg}$ diamorphine and $90 \mathrm{mg}$ morphine sulphate slow release (MST Continous ${ }^{\circledR}$ ). Twelve opiate users exclusively consumed street heroin on a daily basis. One methadonemaintained participant received antidepressant medication (Dothiepin) and another Rabeprazole Sodium for treatment of heartburn. In all, $98 \%$ of opiate users were current smokers (mean \pm SD cigarettes/day 18.5 \pm 11.5 ). All urine samples provided by our opiate users tested positive for methadone or morphine. Twenty also tested positive for cocaine, 18 for benzodiazepines, and one for amphetamine. The 26 ex-drug users, were abstinent from all drugs of abuse for on average 8.2 years (SD 6.3) and urine analyses were negative for all substances. Continuous abstinence was counted from the time of detoxification. Although no medical records were available to verify the reported length 
Table I Percent of Participants per Group Using Legal and Illegal Drugs at Some Point in Their Lives

\begin{tabular}{|c|c|c|c|c|}
\hline & Controls & Amphetamine & Opiate & Ex-drug \\
\hline \multicolumn{5}{|c|}{ Amphetamines } \\
\hline Never & 100 & 0 & 14 & 12 \\
\hline Present & 0 & 100 & 5 & 0 \\
\hline Past & 0 & 0 & 81 & 88 \\
\hline \multicolumn{5}{|l|}{ Opiates } \\
\hline Never & 100 & 44 & 0 & 12 \\
\hline Present & 0 & 0 & 100 & 0 \\
\hline Past & 0 & 56 & 0 & 88 \\
\hline \multicolumn{5}{|l|}{ Ecstasy } \\
\hline Never & 100 & 40 & 48 & 54 \\
\hline Present & 0 & 4 & 0 & 0 \\
\hline Past & 0 & 56 & 52 & 46 \\
\hline \multicolumn{5}{|l|}{ Cocaine } \\
\hline Never & 100 & 16 & 12 & 8 \\
\hline Present & 0 & 36 & 33 & 0 \\
\hline Past & 0 & 48 & 55 & 92 \\
\hline \multicolumn{5}{|c|}{ Benzodiazepines } \\
\hline Never & 100 & 67 & 31 & 35 \\
\hline Present & 0 & 4 & 15 & 0 \\
\hline Past & 0 & 29 & 54 & 65 \\
\hline \multicolumn{5}{|c|}{ Hallucinogens } \\
\hline Never & 100 & 36 & 29 & 23 \\
\hline Present & 0 & 8 & 2 & 0 \\
\hline Past & 0 & 56 & 69 & 77 \\
\hline \multicolumn{5}{|l|}{ Alcohol } \\
\hline Never & 100 & 40 & 40 & 19 \\
\hline Present & 0 & 16 & 7 & 0 \\
\hline Past & 0 & 44 & 53 & 81 \\
\hline \multicolumn{5}{|l|}{ Cannabis } \\
\hline Never & 100 & 20 & 2 & 12 \\
\hline Present & 0 & 52 & 50 & 0 \\
\hline Past & 0 & 28 & 48 & 88 \\
\hline \multicolumn{5}{|l|}{ Nicotine } \\
\hline Never & 37 & 12 & 0 & 4 \\
\hline Present & 22 & 88 & 98 & 62 \\
\hline Past & 41 & 0 & 2 & 34 \\
\hline
\end{tabular}

Both amphetamine and opiate users were meeting the DSM-IV criteria for amphetamine or opiate dependence, but they did not meet DSM-IV criteria for current abuse or dependence of another substance (except nicotine).

of abstinence, in combination with urine analysis and no fear of negative repercussions, self-reported drug use has been considered to be valid (Nelson et al, 1998). In particular, the fact that we recruited within self-support groups of recovering drug users who were highly motivated to participate in this research meant that they were likely to have reported the length of drug abstinence correctly. Eight ex-drug users were ex-stimulant (amphetamine and cocaine) users, five were ex-opiate users and 13 had been dependent on both stimulants and opiates. In all, $62 \%$ of ex-drug users were current tobacco smokers (mean \pm SD $10 \pm 10.4$ cigarettes per day). One ex-drug user was on antidepressant medication (Cipramil). Also, 22\% of controls were smoking tobacco currently (mean \pm SD $3 \pm 6.4$ cigarettes/day). Altogether, 12 of the past/current tobaccosmoking controls $(71 \%)$ reported social experiences with cannabis, but no regular use. One participant had diabetes, which was well controlled on insulin. The urine screens provided by control participants were negative for all substances.

\section{Procedure}

Prior to testing, participants filled out the BDI-II (Beck et al, 1996), which is an established self-rating measure of depression severity. The computerized tasks were run on an Advantech personal computer with a touch-sensitive screen.

One-Touch Tower of London (TOL) (Owen et al, 1995a) is a modified version of the TOL task of spatial planning (Owen et al, 1990). Two arrangements of colored balls are presented on a computer screen and participants are asked to mentally plan and work out the minimum number of moves necessary to make the bottom array look like the top array. At the bottom of the screen there are six squares numbered one to six that stand for the minimum number of moves necessary to solve a given planning problem. The participants are told to touch the square indicating the number of minimum moves necessary to match the bottom array to the top array of balls. The TOL is considered to be more difficult than previous versions of the task. To ensure that all participants understood the task, each was given a block of practice trials in which they had to move the balls around and copy the top arrangement.

Three-dimensional IDED (Rogers et al, 1999a) is a cognitive rule-learning and set-shifting task adapted from the Wisconsin Cart Sorting Test (WCST) (Grant and Berg, 1948). Participants are required to learn a series of different visual dimensions involving stimuli that comprise three dimensions (number, shape, and color) and to shift attention between these dimensions. The task entails eight stages; proceeding to the next stage requires attaining the criterion of six consecutive correct responses. The task starts with a simple discrimination (SD) for stimuli varying in just one dimension. Then, a second alternative dimension to discriminate is introduced in a compound stimuli set (compound discrimination (CD)). This dimension is then tested in a novel set of stimuli (intradimensional shift (IDS)). Finally, participants need to learn a new dimension in a novel set of stimuli (extradimensional shift (EDS)). At each stage of the task, participants are required to inhibit the just learned stimulus-reinforcement association and reverse their responses (reversal shifts). The set-up of the 3D-IDED task is similar to 2D-IDED task, but the inclusion 
of a further stimulus dimension is considered to increase task difficulty.

Paired Associate Learning (PAL) test (Robbins et al, 1997; Sahakian et al, 1988) from the Cambridge Neuropsychological Test Automated Battery (CANTAB; Cambridge Cognition Ltd), assesses episodic memory and learning of geometric patterns and spatial locations. In the first six of the eight trials, six white boxes arranged in a circle on the screen automatically open up one at a time in a random order, each displaying a different geometric pattern. After the last box has disclosed its content, each pattern is displayed in succession in the center of the screen, and participants are asked to select the location where they remember the pattern was previously displayed. Feedback is provided after participants have located all of the patterns. If an error is made, the content of the six patterns is disclosed once again and participants are given another attempt at locating the patterns. Participants are given up to 10 attempts to locate all patterns correctly, and only when all patterns have been correctly located in the same trial can participants proceed to the next trial. In the final two trials, there are eight boxes on the screen with eight different patterns to remember their location. Response accuracy and latency are recorded for this task.

Delayed pattern recognition memory (PRM) (Sahakian et al, 1988), also taken from the CANTAB battery, is a test to assess short-term recognition memory for geometric patterns. Two sets of 12 geometric patterns are displayed consecutively in a box in the middle of the computer screen. Participants are instructed to memorize the patterns. After the presentation of the patterns, participants are given a two-choice test of two patterns, one which they have seen before together with a distractor pattern, and told to pick the pattern they remember having seen previously. The forced two-choice test is repeated after a 15-min delay. The pattern recognition task has shown to be sensitive to damage to temporal lobe structures, including the hippocampus (Owen et al, 1995b).

\section{Statistical Analysis}

Data were analyzed using the Statistical Package for Social Sciences (SPSS) version 11 (SPSS Inc.). While untransformed values are displayed in figures and tables, some data were transformed in preparation for parametric analysis as described by Howell (1997). Thus, accuracy data, years of substance abuse, age of onset of amphetamine use and opiate use, as well as BDI depression scores were square root transformed and latency data were log-transformed. Pearson correlations were two-tailed and a significance level of 0.05 was assumed. The correlations for drug users and controls were calculated separately. One-way analyses of variance (ANOVA) were used to explore group differences in age, verbal IQ, and depression as measured by the BDI-II. Group differences regarding handedness, gender, and the results of the urine screens were analyzed via $\chi^{2}$ or Fisher's exact procedures. The TOL and the PRM tasks were subject to repeated-measures ANOVA. If the Mauchly test showed violation of the sphericity assumption, Greenhouse-Geisser epsilon corrections were used. Univariate ANOVAs were conducted to further investigate significant results. The IDED and the PAL tasks were analyzed by multivariate analyses of variances (MANOVA). Post-hoc analyses of the effects of gender and positive urine samples of cocaine in opiate users and of opiates in amphetamine users were run on a single summary variable from each task to reduce the false-positive rate: TOL perfect solutions, IDED total errors, PRM delayed accuracy, and PAL first trial memory score.

Three planned orthogonal contrasts were conducted: (1) all three drug user groups compared to controls, (2) current drug users vs ex-drug users, and (3) current amphetamine users contrasted with current opiate users. In the event of group differences in the descriptive data, Tukey's post-hoc test was conducted if variances were equivalent between groups and Tamhane's test if variances differed between groups. Post-hoc procedures were thresholded at level $p<0.05$. Due to various computer problems data sets are not fully complete.

\section{RESULTS}

There were no significant group differences regarding age, verbal IQ, gender, or handedness, which are displayed in Table 2. Drug users also did not differ on years of drug abuse, showing that the groups were well matched. Neither was there a significant group difference regarding the age of onset of amphetamine use. However, the groups significantly differed regarding the age when they started using opiates $\left(\mathrm{F}_{2,77}=9.17 ; p<0.001\right)$. Not all ex-drug users had used opiates regularly, but those who did began using them significantly earlier than current amphetamine users (Tamhane's $p=0.008$ ) who reported taking opiates to calm down following an amphetamine binge. The ex-drug users also started using opiates earlier than the current opiate users, at trend level significance (Tamhane's $p=0.052$ ). The groups differed in regard to BDI depression scores $\left(F_{3,116}=14.22, p<0.001\right)$. Drug users scored higher on the BDI than controls $\left(t_{116}=5.09, p<0.001\right)$ and current drug users reported greater levels of depression symptoms than ex-drug users $\left(t_{116}=3.69, p<0.001\right)$. Since depression has been shown to affect performance on the tasks administered (Murphy et al, 1999; Purcell et al, 1997; Sweeney et al, 2000), the BDI total score was included into the analysis as a covariate.

\section{Tower of London}

Univariate ANOVA on the percentage of correctly solved planning problems at first attempt revealed a main effect of group $\left(\mathrm{F}_{3,113}=8.56, p<0.001\right)$. Drug users solved fewer problems than controls $\left(t_{69.6}=-5.89, p<0.05\right)$ and amphetamine users solved fewer problems than opiate users $\left(t_{42.7}=-2.34, p<0.05\right)$. There was no difference between current and former drug users. Repeated-measures ANOVA on the different levels of difficulty revealed a significant main effect of difficulty $\left(\mathrm{F}_{3.3,372.5}=10.97, p<0.001\right)$ and a group $\times$ difficulty interaction at trend level $\left(\mathrm{F}_{9.9,372.5}=1.66\right.$, $p=0.088$ ). Univariate ANOVAs were then conducted to analyze the levels of difficulty separately. Performance on planning problems requiring one-move and two-moves did not differ between the groups $\left(\mathrm{F}_{3,112}=1.44, p=0.236\right.$; $\left.\mathrm{F}_{3,112}=1.333, p=0.268\right)$. Significant differences emerged on three-moves $\left(\mathrm{F}_{3,112}=6.39, p<0.001\right)$, four-moves $\left(\mathrm{F}_{3,112}=3.45\right.$, $p=0.019)$, and five-moves $\left(\mathrm{F}_{3,112}=5.19, p=0.002\right)$, and $\mathrm{a}$ 
Table 2 Mean Total Scores ( \pm Standard Deviation) of Descriptive Group Characteristics (Ratio of Participants' Gender, Handedness, and Percentage of Participants Who were Currently Employed)

\begin{tabular}{|c|c|c|c|c|}
\hline & Controls & Amphetamine & Opiate & Ex-drug \\
\hline Verbal IQ $Q^{b}$ & I $4.4(6.5)$ & I I I.2 (5.3) & | $13.0(6.0)$ & I $3.5(7.5)$ \\
\hline Age (years) & $35.1(8.9)$ & $37.0(7.9)$ & $33.8(7.8)$ & $38.0(6.5)$ \\
\hline Gender (M:F) & $14: 13$ & $14: 11$ & $33: 9$ & $14: 12$ \\
\hline Years of drug abuse $^{c}$ & - & $16.9(9.1)$ & $10.8(8.6)$ & $10.1(5.3)$ \\
\hline \multicolumn{5}{|l|}{ Age of onset: ${ }^{d}$} \\
\hline Amphetamine use & - & $18.4(5.1)^{n=25}$ & $18.1(4.2)^{n=15}$ & $16.8(2.9)^{n=23}$ \\
\hline Opiate use & - & $27.1(7.9)^{n=14}$ & $22.1(4.7)^{n=42}$ & $19.4(4.2)^{n=23}$ \\
\hline
\end{tabular}

aBDI II, total score (Beck et al, 1996).

bVerbal IQ was estimated using the National Adult Reading Test (NART) (Nelson, 1982).

'Years of drug abuse were assessed from the time when the drug of choice was regularly used (defined as at least four times a week).

${ }^{\mathrm{d}}$ Age of onset was assessed from the time when the drug was used frequently after it was first tried (as defined by at least once a week).

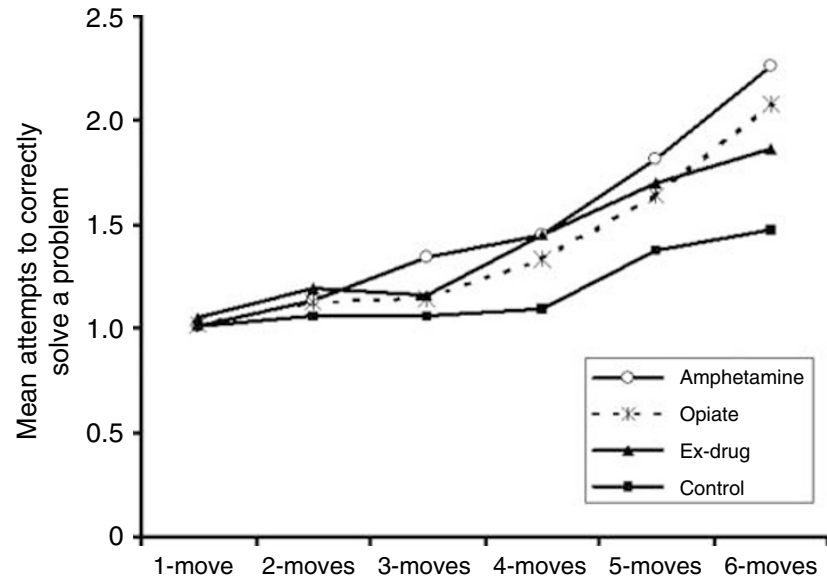

Figure I Mean attempts to success per group on I-6-move planning problems on the one-touch TOL planning task. Planning performance for one-move and two-move problems was not different between the groups. For solving 3-6-move planning problems, all three drug user groups needed significantly more attempts than controls (all $p<0.00 \mathrm{I}$ ). Performance did not differ between current and former drug users, but amphetamine users needed significantly more attempts on three-move problems relative to opiate users $(p<0.05)$.

trend on six-move problems $\left(\mathrm{F}_{3,112}=2.96, p=0.082\right)$. As Figure 1 shows, the group differences were due to the fact that drug users needed more attempts to solve the planning problems than controls (three-moves: $t_{76.6}=4.09$; fourmoves: $t_{83.6}=4.49$; five-moves: $t_{62.7}=4.30$ all $p<0.01$ ). There were no group differences in performance between current and former drug users at any stage. The contrast between amphetamine users and opiate users, however, revealed significantly more attempts in amphetamine users on three-move problems $\left(t_{37.8}=2.75, p<0.05\right)$. Repeatedmeasures ANOVA was applied on latency at first response for the levels of difficulty (six levels) as the withinsubject factor and group as the between-subject factor. There was a main effect of difficulty on latency at first attempt $\left(\mathrm{F}_{2.1,161.1}=77.57, \quad p<0.001\right)$, but no group $\times$ difficulty interaction.

\section{Three-Dimensional IDED Task}

A total of $63 \%$ of the controls passed the entire task compared to $64 \%$ amphetamine users, $67 \%$ opiate users, and $65 \%$ of ex-drug users $\left(\chi^{2}=0.113, p=0.990\right)$. Descriptive information on mean errors and latencies of the critical IDS and EDS stages are displayed in Table 3. Pass rates did not differ between the groups at any stage (data not shown). Performances in terms of errors made at each stage were analyzed by the use of MANOVA procedure. There was a significant group effect on the ID shift $\left(\mathrm{F}_{3,77}=3.13\right.$, $p=0.030$; Pillai's Trace $=0.38, p=0.171)$, which was due to amphetamine users making significantly more errors than opiate users $\left(t_{46.4}=2.75, p<0.05\right)$. The other two planned comparisons were not significant. Neither was there a significant group difference regarding the total number of errors made $\left(\mathrm{F}_{3,77}=1.46, p=0.233\right)$ nor on the total reversal errors $\left(\mathrm{F}_{3,77}=0.32, p=0.809\right)$. For response latencies, there was a group difference on the ED-reversal stage $\left(\mathrm{F}_{3,77}=3.10, p=0.032\right.$; Pillai's trace $\left.=0.36, p=0.218\right)$. Controls had longer ED-reversal latencies than the other groups (mean in seconds $\pm \mathrm{SD}$, controls: $1.75 \pm 1.45$, amphetamine: $1.37 \pm 0.59$, opiates: $1.22 \pm 0.39$, ex-drug: $1.15 \pm 0.34)$, but this difference was not significant in the planned comparison. In addition, it is worth noting that, although the amphetamine users tended to have higher error rates throughout the test (see Table 3), none of the three planned comparisons was significant.

\section{Paired Associate Learning}

All control participants successfully completed the entire task compared to $88 \%$ of amphetamine users, $88 \%$ of opiate users, and $89 \%$ of ex-drug users. Pass rates did not differ significantly between the groups (Fisher's exact 
Table 3 Mean ( \pm Standard Deviation) of Main Task Measures per Group

\begin{tabular}{|c|c|c|c|c|c|c|}
\hline Task & Main measures & Controls & Amphetamine & Opiate & Ex-drug & $p$-values \\
\hline \multirow[t]{5}{*}{$\overline{\mathrm{TOL}}$} & Perfect solutions at first attempt (\%) & $86.11(9.32)$ & $67.21(13.84)$ & $75.40(12.88)$ & $71.83(18.88)$ & $<0.001$ \\
\hline & Mean attempts ( $1-3$ moves) & $1.04(0.14)$ & $1.16(0.12)$ & $1.10(0.12)$ & $1.13(0.06)$ & 0.002 \\
\hline & Mean attempts (4-6 moves) & $1.31(0.63)$ & $1.90(0.47)$ & $1.68(0.52)$ & $1.67(0.28)$ & $<0.001$ \\
\hline & Mean latency (s) ( $1-3$ moves) & $8.20(1.77)$ & $7.52(1.66)$ & $8.13(2.19)$ & $7.80(1.95)$ & 0.580 \\
\hline & Mean latency (s) (4-6 moves) & $33.38(13.354)$ & $34.66(17.28)$ & $31.08(17.47)$ & $30.07(17.57)$ & 0.752 \\
\hline \multirow{4}{*}{ 3D-ID/ED } & $C D$ mean errors & $2.56(5.7 I)$ & $3.04(5.94)$ & $2.93(6.64)$ & $2.08(3.11)$ & 0.585 \\
\hline & IDS mean errors & $1.65(3.47)$ & $2.52(3.36)$ & $1.26(2.58)$ & $1.83(4.82)$ & 0.030 \\
\hline & EDS mean errors & $7.85(8.67)$ & $12.17(9.88)$ & $9.89(9.19)$ & $8.82(8.16)$ & 0.420 \\
\hline & Total reversal errors (sum of the 4 stages) & $7.00(5.24)$ & $9.63(4.5 \mathrm{I})$ & $7.82(5.40)$ & $9.39(7.68)$ & 0.809 \\
\hline \multirow[t]{3}{*}{ PAL } & Percent of stages passed on first trial & $71.11(21.72)$ & $57.60(21.07)$ & $60.00(20.24)$ & $65.38(14.49)$ & 0.070 \\
\hline & first trial memory score (mean) & $16.96(3.37)$ & $12.84(4.20)$ & |3.8| (3.68) & $14.46(3.74)$ & 0.011 \\
\hline & Total trials to success (mean) & $7.52(2.58)$ & $11.04(3.61)$ & $10.29(3.79)$ & $9.81(2.98)$ & 0.005 \\
\hline \multirow[t]{4}{*}{ PRM } & Percent of correctly recognized patterns (immediate) & $93.21(8.81)$ & $80.00(11.72)$ & $86.41(12.14)$ & $87.34(10.24)$ & 0.001 \\
\hline & Percent of correctly recognized patterns (delay) & $92.75(7.89)$ & $82.00(\mid 4.86)$ & $83.33(11.16)$ & $84.29(12.49)$ & 0.025 \\
\hline & Latency (s) (immediate) & $2.06(0.45)$ & $2.22(0.65)$ & $2.28(0.56)$ & $2.08(0.50)$ & 0.404 \\
\hline & Latency (s) (delay) & $2.17(0.54)$ & $2.14(0.61)$ & $2.21(0.5 \mathrm{I})$ & $2.06(0.52)$ & 0.682 \\
\hline
\end{tabular}

Bold indicates values with $p<0.05$.

test, $p=0.263)$. However, there were significant differences on the three main measures: the first trial memory score, total errors, and total trials. As revealed by MANOVA procedures, there was a group effect on the number of stimuli correctly located after first presentation $\left(\mathrm{F}_{3,115}=3.89, p=0.011\right.$, Pillai's trace $\left.=0.15, p=0.045\right)$ such that drug users had a significantly lower first trial memory score than controls $\left(t_{116}=-3.96, p<0.05\right)$. As displayed in Figure 2, the group effect on total errors $\left(F_{3,115}=4.26\right.$, $p=0.007$, Pillai's trace $=0.15, p=0.045)$ was due to a significantly greater number of errors made by drug users relative to controls $\left(t_{116}=4.52, p<0.05\right)$. The groups significantly differed in the number of trials needed to learn the paired associates $\left(F_{3,115}=4.52, p=0.005\right.$, Pillai's trace $=0.15, p=0.045)$, with drug users needing significantly more trials than controls $\left(t_{116}=4.17, p<0.05\right)$. On all three measures, the other two planned comparisons did not reveal significant group differences.

\section{Immediate and Delayed Pattern Recognition (PRM)}

Repeated-measures ANOVA was conducted on accuracy and latency of the recognized patterns with delay as a within-subject factor (two levels) and group as a betweensubject factor. The ANOVA revealed a significant main effect of delay for latency $\left(\mathrm{F}_{1,115}=857.75, p<0.001\right)$ and a significant delay $\times$ group interaction on accuracy $\left(F_{3,115}=5.72, p=0.001\right)$. Univariate ANOVA on the per-

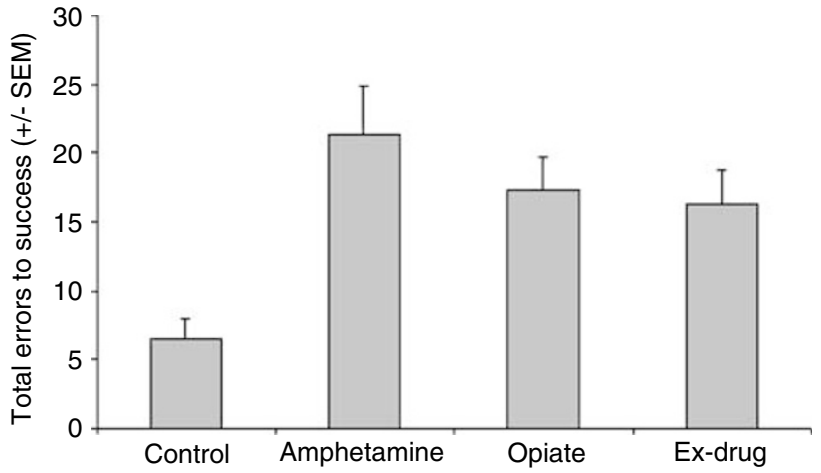

Figure 2 Total errors made to successfully complete the PAL task. All three drug user groups made a significantly greater number of errors compared to controls in learning the correct associations between the patterns and their spatial locations $(p=0.007)$.

centage of correctly recognized patterns after immediate presentation showed a group difference $\left(F_{3,115}=6.26\right.$, $p=0.001)$. Drug users recognized fewer patterns relative to controls $\left(t_{116}=-3.78, p<0.05\right)$ and amphetamine users recognized fewer patterns relative to opiate users $\left(t_{116}=-2.41, p<0.05\right)$. There was also a significant group difference on patterns recognized after a 15-min delay $\left(F_{3,115}=3.24, p=0.025\right)$ such that drug users recognized fewer patterns relative to controls $\left(t_{116}=-3.87, p<0.05\right)$. Recognition memory did not differ between current and 
Table 4 Mean ( \pm Standard Deviation) per Group in Respect to Gender of the Number of Patterns Correctly Located after First Presentation (First Trial Memory Score) and the Number of Patterns Correctly Recognized Following Presentation and Following a I5-min Delay

\begin{tabular}{|c|c|c|c|c|c|c|c|c|c|}
\hline \multirow[b]{2}{*}{ Task } & \multirow[b]{2}{*}{ Measures } & \multicolumn{2}{|c|}{ Controls } & \multicolumn{2}{|c|}{ Amphetamine } & \multicolumn{2}{|c|}{ Opiate } & \multicolumn{2}{|c|}{ Ex-drug } \\
\hline & & Men & Women & Men & Women & Men & Women & Men & Women \\
\hline PRM & $\begin{array}{l}\text { Percent of correctly } \\
\text { recognized patterns (delay) }\end{array}$ & $95.24(6.5 \mathrm{I})$ & $90.06(8.60)$ & $77.08(16.49)$ & $88.26(10.00)$ & $83.21(11.29)$ & $83.80(11.30)$ & $82.44(12.14)$ & $86.46(13.7)$ \\
\hline
\end{tabular}

former drug users, but amphetamine users tended to recognize more patterns after the delay than after immediate presentation (see Table 3). According to the univariate ANOVA on the difference score, the number of recognized patterns after the delay minus number of immediately recognized patterns was not significant.

\section{Correlational Analyses}

Neither years of drug use nor years of drug abstinence were associated with any outcome measure. To assess the influence of current tobacco smoking on task performance in all participants, correlational analyses were carried out on the number of cigarettes smoked per day and a summary measure of each task, with no significant effects found.

\section{Gender Effects}

Although the groups were matched for gender, nonetheless the data were analyzed in order to explore gender differences. Results of these analyses showed that neither in controls nor in drug users did male and female participants differ regarding BDI scores, age, or verbal IQ. Male and female drug users also did not differ in respect to duration of drug use. Univariate ANOVA was applied to the summary measures of each task with both group and gender as independent variables. A significant group $\times$ gender interaction on the first trial memory score $\left(F_{3,112}=3.70\right.$, $p=0.014)$ and a marginal significant group $\times$ gender interaction on PRM delayed accuracy $\left(\mathrm{F}_{3,112}=2.26\right.$, $p=0.085)$ were found. The means and SD of the performance measures are displayed in Table 4. To explore the nature of the effects, univariate ANOVAs were carried out for controls and drug users separately using gender as independent variable. Figure 3 shows that in controls, men remembered more paired associates following first presentation than their female counterparts $\left(\mathrm{F}_{1,25}=5.21\right.$, $p=0.031)$. In drug users the relationship was reversed: women had a significantly higher first trial memory score than the male drug users $\left(\mathrm{F}_{1,91}=5.56, p=0.021\right)$. While there was no significant difference in performance between female controls and female drug users on the memory score, male drug users performed significantly worse than male controls $\left(\mathrm{F}_{1,73}=23.10 ; p<0.001\right)$. The PRM delayed accuracy, shown in Table 4, illustrates that the gender effect was of a similar nature to the first trial memory score.

In summary, drug users showed marked impairments on the TOL, PAL, and PRM compared to controls, while performance on the 3D-IDED task did not significantly

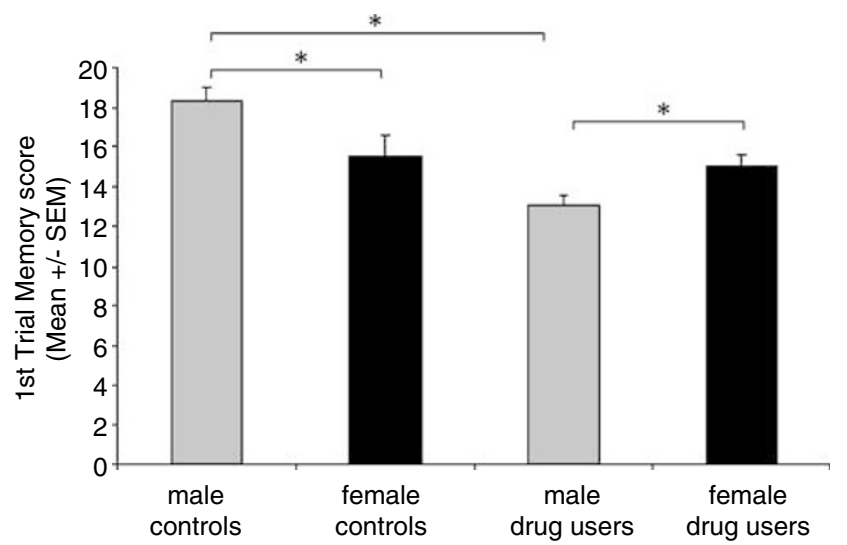

Figure 3 Gender differences regarding how many paired associates (PAL) had been remembered following first presentation. In controls, men remembered significantly more paired associates than women $(p=0.03 \mathrm{I})$. In drug users, the performance profile was reversed: women remembered more paired associates than men $(p=0.021)$. While there was no significant difference between drug using women and female controls, male drug users performed significantly worse than male controls $(p<0.001)$. Note: Neither in the control group nor in the drug user group did male and female participants differ regarding BDI scores, age, or verbal IQ. Male and female drug users did not differ with respect to duration of drug use. * $p<0.05$

differ from controls. No significant differences between current and former drug users were found on any of the tasks. Compared to opiate users, amphetamine users showed more pronounced deficits on tasks of executive function including attentional set-shifting, PRM and visuospatial planning in the TOL task. Subsequent analyses regarding the positive urine screens for opiates in amphetamine users and for cocaine in opiate users were non-significant.

\section{DISCUSSION}

Consistent with our hypothesis, drug users showed marked impairments in spatial planning, PAL, and visual pattern recognition relative to controls. Performance of former drug users was not significantly different from current drug users on any task measure, suggesting that the neurocognitive impairment does not simply reflect the current effects of the substances abused. As hypothesized, current amphetamine users showed more profound impairments than opiate users on spatial planning, pattern recognition memory, and attentional set-shifting. 
Comparison of Cognitive Performance of Chronic Drug Users with Controls

On the TOL spatial planning task, all three drug user groups solved significantly fewer problems correctly, and therefore needed more attempts relative to controls. However, on the easy stage of the task, performance was intact. Despite having problems with spatial planning, drug users did not deliberate longer on the problems. This stands in contrast to other patient groups with a fronto-striatal pathology, such as patients with Parkinson's Disease or with schizophrenia, who also perform poorly on the TOL (Owen et al, 1992, 1995a; Pantelis et al, 1997). The fact that our drug users and controls did not differ on response latency may indicate that drug users did not reflect sufficiently long to solve the problems accurately. The significantly higher number of errors on the TOL in our drug user groups compared to controls is in keeping with evidence for prefrontal dysfunction in chronic drug users (Ersche et al, 2005; Hester and Garavan, 2004; Paulus et al, 2002) since the right DLPFC has shown to be critically involved in spatial planning on the TOL (Baker et al, 1996; Manes et al, 2002).

Drug users' performance on the 3D-IDED task did not significantly differ from controls, although it has been reported that the right DLPFC is implicated in the critical EDS stage (relative to IDS) (Rogers et al, 2000). It is possible that group differences in performance on the 3D-IDED task did not emerge because only $78 \%$ of our controls, who were specifically selected to match the drug user groups, passed the EDS stage. The relatively high number of controls failing the EDS stage led to an overall pass rate of the task of $63 \%$. Previous research with this task indicates a pass rate around $80 \%$ in healthy volunteers, albeit in participants with a high level of education (Mehta et al, 1999). On the other hand, unimpaired performance of substance users in comparison to healthy controls has been found on the WCST (Grant and Berg, 1948), which contains a similar set-shifting component to the 3D-IDED task (Simon et al, 2002, in cocaine users; Rotheram-Fuller et al, 2004, in methadone-maintained opiate users; Pau et al, 2002, in former heroin users). Our results, however, contrast with the impaired performance on a related but different test of attentional setshifting in chronic substance users relative to healthy controls reported by Ornstein et al (2000). There are a number of possible explanations for the differing findings. One possibility may be due to the fact that we used a different task, which includes three stimulus dimensions similar to the WCST. Using a two-dimension task, Ornstein et al (2000) reported an overall pass rate of $90 \%$ in controls, which may assist the detection of deficits in attentional setshifting. It is thus likely that, due to the poor performance of our controls on the EDS stage, the high number of EDS errors in amphetamine users, as shown in Table 3, did not reach significance. In addition, sample size, demographic, and clinical characteristics of the groups differed between the two studies. However, in accordance with Ornstein et al (2000), we did not find significant group differences on reversal errors, which are considered to reflect orbitofrontal dysfunction (Hornak et al, 2004).

Severe impairments in drug users relative to controls were evident in the PAL task, which requires forming associations between a stimulus (what) and a spatial location (where). Drug users not only performed poorly at locating patterns correctly after first presentation, but they also made significantly more errors and needed more trials to learn the correct associations (what goes where). Experimental research in animals has found that the encoding and retrieval of object-spatial paired associations (what is where) requires the hippocampal formation in the temporal lobe (Day et al, 2003; Parkinson et al, 1988); areas which are not only involved in learning and memory but also undergo structural changes in the course of drug addiction (Everitt et al, 1999; Nestler, 2002; Robbins and Everitt, 2002; Vorel et al, 2001). Recent evidence also suggests that mesiotemporal areas are the most affected by the metabolic changes following chronic cocaine use (Porrino et al, 2004). In particular, neural changes in the hippocampus associated with chronic drug use are considered to be long-lasting (Nestler, 2001, 2002). It should also be noted that the hippocampi are among the first brain regions that are affected by Alzheimer's Disease (Ball, 1977; Hyman et al, 1984), and the PAL task has recently demonstrated a high sensitivity to the early memory decline in Alzheimer's disease (Blackwell et al, 2004). Moreover, early signs of memory impairment and associate learning are also detectable with the PAL task in patients with schizophrenia following the first psychotic episode (Barnett et al, 2005). For recognition memory, impairments in both conditions, immediately and after a 15-min delay, were obvious in drug users. Drug users recognized significantly fewer patterns than our drug-naive controls in both conditions, thereby extending the findings by Ornstein et al (2000), who only investigated immediate recognition memory performance. The poor performance of our drug users on the PAL and the PRM task provides further evidence that substance dependence is associated with deficient learning and memory of the declarative type (Nestler, 2001, 2002; Robbins and Everitt, 2002).

In view of the accumulating evidence that indicates that chronic drug use has more adverse effects on the male than on the female human brain (Chang et al, 1999; Kaufman et al, 2001; Kim et al, 2005; King et al, 2000; Levin et al, 1994; Lyoo et al, 2004), we matched our groups for gender. We took the opportunity to explore gender differences post hoc and confirmed findings from previous research that healthy male volunteers perform better on visuo-spatial tests than their female counterparts (Delgado and Prieto, 1996; Weiss et al, 2003). This relationship, however, was reversed in drug users. Figure 3 shows that male drug users showed significantly greater impairment in remembering paired associates than female drug users, whose performance was not significantly different from female controls. At trend level the same gender effects were also evident on accuracy in delayed PRM (Table 4). Our finding therefore suggests that visual memory impairment associated with chronic drug use is limited to the male gender. Given that findings from experimental animal studies show greater neurotoxic effects in male compared to female brains (Heller et al, 2001; Wagner et al, 1993), it seems unlikely that the more severe impairment seen in our male drug users is simply due to more heavy drug use in men. Recently, it has been suggested that the gonadal steroid hormone estrogen, in contrast to testosterone, has a neuroprotective effect on drug toxicity (Dluzen et al, 2002; 
Dluzen and Horstink, 2003; Dluzen and McDermott, 2004; Myers et al, 2003; Yu and Liao, 2000). Our study extends previous research that has reported greater neurocognitive impairment in male drug users compared to male controls (Kim et al, 2005; Stout et al, 2005) and has, to the best of our knowledge, provided new evidence suggesting the dramatic decline in visuo-spatial memory in male drug users via the reversed gender effect between drug-naive controls and chronic drug users.

\section{Cognitive Function in Chronic Amphetamine Users Relative to Opiate Users}

Consistent with our hypothesis, amphetamine users showed more marked impairments compared to opiate users, which reached significance on spatial planning (three-move problems) and PRM. The deficits exhibited at these easy task stages may either reflect an overconfident approach towards the solution or inefficiency in concentrating on the task demands. The current user groups further differed in performance on the 3D-IDED task. Amphetamine users, relative to opiate users, made significantly more errors when required to generalize an already learned attentional set to a novel set of stimuli (IDS stage) and numerically more errors when they needed to learn a new dimension in a novel set of stimuli (EDS stage). It is interesting to note that, in patients with schizophrenia, errors on the IDS stage are associated with disorganized symptom characteristics of the disorder (Pantelis et al, 2004), while impairment on the EDS stage is considered to reflect the progressive deterioration of the illness (Pantelis et al, 1999, 2003, 2004). Chronic use of amphetamines can induce psychotic states similar to the psychosis seen in patients with schizophrenia (Curran et al, 2004; Robinson and Becker, 1986), in contrast to morphine which has been regarded as having antipsychotic properties (Comfort, 1977; Aguilar et al, 2004). This difference in the effects of the two substances seems to be mirrored in the performance of chronic users of these substances on this attentional set-shifting task.

Our findings, however, contrast with the double dissociation reported by Ornstein et al (2000), that opiate users fail on the IDS and amphetamine users on the EDS stage. Our amphetamine users did show a marked tendency toward increased errors on the EDS stage, but our opiate users did not display signs of impairment on the IDS stage. At first glance, these differing findings may be surprising, but performance on the WCST (Grant and Berg, 1948) has also been shown to fluctuate in chronic drug users. There is some indication that performance may depend upon whether participants are 'on the drug' during time of testing. For example, Lyvers and Yakimoff (2003) found that methadone-maintained opiate users in early withdrawal made more mistakes on the WCST than opiate users who were on a sufficient dose of methadone at the time of testing. Correspondingly, methamphetamine users on the drug performed worse than controls (Simon et al, 2002), whereas 25-day abstinent crack-cocaine users showed an even better performance on the WCST than controls (Hoff et al, 1996). This suggests that not only the difference in the task version but also group characteristics regarding demographic as well as clinical variables (ie dependency on more than one substance), type of substances currently used, and the state of drug intoxication need to be taken into consideration when explaining differing findings between these two studies. In line with Ornstein et al (2000), our findings show clear deficits in executive function in chronic opiate users at normal response latency, whereas previous research has found qualitatively unimpaired performance at the expense of increased response time in this patient group (Mintzer and Stitzer, 2002, re psychomotor speed Rogers et al, 1999b, re decision-making; Specka et al, 2000, re visual structuring). Future studies could address the question of whether specific encouragement of opiate users to increase deliberation time can reduce the level of impaired executive function.

\section{Cognitive Function in Current Drug Users Relative to Former Drug Users}

Performance in the former drug user group was not significantly different from current user groups, suggesting that impairments probably do not simply reflect current effects of the drug. Urine analyses prior to testing confirmed current drug taking in the amphetamine and opiate groups and drug abstinence in the former drug users. Retrospective reports indicated at least 1 year abstinence (on average over 8 years) in the former drug users. As such, we argue that the neuropsychological impairments are probably the result of chronic drug exposure. Particularly the fact that $50 \%$ of the former drug users had been dependent on both stimulants and opiates, using both together intravenously, may have exacerbated negative consequences of chronic drug use (Leri et al, 2003). Recovery of cognitive function may therefore be limited despite the prolonged abstinence. The length of drug abstinence was not associated with improved cognitive performance, in keeping with previous research (Hoff et al, 1996; Medina et al, 2004). The similarities between the current and former drug users are also consistent with the notion of pre-existing neurocognitive impairments in drug users, which predate drug taking and may represent vulnerability markers. There is evidence for executive dysfunction in adolescent groups at high risk for substance abuse (Nigg et al, 2004; Tarter et al, 2003).

\section{General Comments and Summary}

One limitation of the present study was an inevitable degree of polydrug use in the current users. However, the amphetamine and opiate groups both met the DSM-IV criteria for dependence, respectively, for those different drug classes. We also excluded participants who met DSMIV criteria for dependence on substances other than amphetamines/opiates, although the current drug users reported recreational use of several drugs including ecstasy, cocaine, and cannabis unlike the controls. This polydrug use was reasonably balanced across the current amphetamine and opiate groups, and seems unlikely to have confounded the exaggerated cognitive deficits in the current amphetamine users. Although we included the BDI total score as a covariate in the analyses, the patterns of cognitive impairment displayed by our current drug users were different from the performance of patients suffering from major depression (Purcell et al, 1997; Sweeney et al, 2000), but did not differ from the non-depressed ex-drug users. 
Our findings may therefore suggest that the substantial cognitive impairments associated with dependence on amphetamines and opiates are independent of depression. Our findings may further explain why treatment approaches which make use of a cognitive visual representation technique or which include cognitive training modules targeting strategies to improve memory and planning have shown to be very effective (Czuchry and Dansereau, 1999, 2003; Dansereau and Dees, 2002; Joe et al, 1997; Peel et al, 1996; Pitre et al, 1997). In summary, we found that participants engaged in current or previous drug use showed marked impairment in spatial planning, paired associates learning, and pattern recognition memory.

\section{ACKNOWLEDGEMENTS}

We are grateful to the volunteers who took part in this study, particularly to those who aided with recruitment, as well as to the key workers Nick Schiller and Marion Martin and members of Narcotics Anonymous. We also thank Dr Jonathan Roiser for assistance with data extraction. This work was funded by a Wellcome Trust Programme Grant to Professors TWR, BJ Everitt, BJS and Dr AC Roberts, and carried out within the MRC/Wellcome Trust Behavioural and Clinical Neuroscience Institute. KDE was supported by the Fund for Addenbrooke's and the Grindley Fund. BJS and TWR are consultants for Cambridge Cognition Ltd.

\section{REFERENCES}

Aguilar MA, Minarro J, Simon VM (2004). Morphine potentiates the impairing effects of neuroleptics on two-way active conditioned avoidance response in male mice. Prog Neuropsychopharmacol Biol Psychiatry 28: 225-237.

American Psychiatric Association (1994). Diagnostic and Statistical Manual of Mental Disorders, 4th ed. American Psychiatric Association: Washington, DC.

Baker SC, Rogers RD, Owen AM, Frith CD, Dolan RJ, Frackowiak RSJ et al (1996). Neural systems engaged by planning: a PET study of the Tower of London task. Neuropsychologia 34: 515-526.

Ball MJ (1977). Neuronal loss, neurofibrillary tangles and granulovacuolar degeneration in the hippocampus with ageing and dementia. A quantitative study. Acta Neuropathol (Berl) 37: 111-118.

Barnett JH, Sahakian BJ, Werners U, Hill KE, Brazil R, Gallagher O et al (2005). Visuospatial learning and executive function are independently impaired in first-episode psychosis. Psychol Med 35: 1031-1041.

Bechara A, Damasio H (2002). Decision-making and addiction (part I): impaired activation of somatic states in substance dependent individuals when pondering decisions with negative future consequences. Neuropsychologia 40: 1675-1689.

Bechara A, Dolan S, Denburg N, Hindes A, Anderson SW, Nathan PE (2001). Decision-making deficits, linked to a dysfunctional ventromedial prefrontal cortex, revealed in alcohol and stimulant abusers. Neuropsychologia 39: 376-389.

Bechara A, Dolan S, Hindes A (2002). Decision-making and addiction (part II): myopia for the future or hypersensitivity to reward? Neuropsychologia 40: 1690-1705.

Beck AT, Steer RA, Brown GK (1996). Manual for Beck Depression Inventory-II. Psychological Corporation: San Antonio, TX.

Blackwell AD, Sahakian BJ, Vesey R, Semple JM, Robbins TW, Hodges JR (2004). Detecting dementia: novel neuropsychological markers of preclinical Alzheimer's disease. Dementia Geriatr Cogn Disord 17: 42-48.

Bullmore E, Suckling J, Zelaya F, Long C, Honey G, Reed L et al (2003). Practice and difficulty evoke anatomically and pharmacologically dissociable brain activation dynamics. Cereb Cortex 13: $144-154$

Chang L, Ernst T, Strickland T, Mehringer CM (1999). Gender effects on persistent cerebral metabolite changes in the frontal lobes of abstinent cocaine users. Am J Psychiatry 156: $716-722$

Comfort A (1977). Morphine as an antipsychotic. Relevance of a 19th-century therapeutic fashion. Lancet 2: 448-449.

Curran C, Byrappa N, McBride A (2004). Stimulant psychosis: systematic review. Br J Psychiatry 185: 196-204.

Czuchry M, Dansereau DF (1999). Node-link mapping and psychological problems-Perceptions of a residential drug abuse treatment program for probationers. J Substance Abuse Treat 17: 321-329.

Czuchry M, Dansereau DF (2003). Cognitive skills training: impact on drug abuse counseling and readiness for treatment. Am J Drug and Alcohol Abuse 29: 1-18.

Danos P, Van Roos D, Kasper S, Bromel T, Broich K, Krappel C et al (1998). Enlarged cerebrospinal fluid spaces in opiatedependent male patients: a stereological CT study. Neuropsychobiology 38: 80-83.

Dansereau DF, Dees SM (2002). Mapping training: the transfer of a cognitive technology for improving counseling. J Substance Abuse Treat 22: 219-230.

Day M, Langston R, Morris RGM (2003). Glutamate-receptormediated encoding and retrieval of paired-associate learning. Nature 424: 205-209.

De Vries TJ, Shippenberg TS (2002). Neural systems underlying opiate addiction. J Neurosci 22: 3321-3325.

Delgado AR, Prieto G (1996). Sex differences in visuospatial ability: Do performance factors play such an important role? Memory Cogn 24: 504-510.

Dluzen DE, Anderson LI, Pilati CF (2002). Methamphetaminegonadal steroid hormonal interactions: effects upon acute toxicity and striatal dopamine concentrations. Neurotoxicol Teratol 24: 267-273.

Dluzen DE, Horstink MWIM (2003). Estrogen as neuroprotectant of nigrostriatal dopaminergic system - Laboratory and clinical studies. Endocrine 21: 67-75.

Dluzen DE, McDermott JL (2004). Developmental and genetic influences upon gender differences in methamphetamineinduced nigrostriatal dopaminergic neurotoxicity. Ann NY Acad Sci 1025: 205-220.

Ersche KD, Fletcher PC, Lewis SJG, Clark L, Stocks-Gee G, London $\mathrm{M}$ et al (2005). Abnormal frontal activations related to decisionmaking in current and former amphetamine and opiate dependent individuals. Psychopharmacology, 15 March [Epub ahead of print].

Everitt BJ, Parkinson JA, Olmstead MC, Arroyo MERC, Robledo PATR, Robbins TW (1999). Associative processes in addiction and reward the role of amygdala-ventral striatal subsystems. Ann NY Acad Sci 877: 412-438.

Fein G, Di Sclafani V, Meyerhoff DJ (2002). Prefrontal cortical volume reduction associated with frontal cortex function deficit in 6-week abstinent crack-cocaine dependent men. Drug Alcohol Depend 68: 87-93.

Fillmore MT (2003). Drug abuse as a problem of impaired control: current approaches and findings. Behav Cogn Neurosci Rev 2: 179-197.

Goldstein RZ, Leskovjan AC, Hoff AL, Hitzemann R, Bashan F, Khalsa SS et al (2004). Severity of neuropsychological impairment in cocaine and alcohol addiction: association with metabolism in the prefrontal cortex. Neuropsychologia 42: 1447-1458. 
Gould RL, Brown RG, Owen AM, ffytche DH, Howard RJ (2003). FMRI BOLD response to increasing task difficulty during successful paired associates learning. Neuroimage 20: 1006-1019.

Grant BF, Stinson FS, Dawson DA, Chou SP, Dufour MC, Compton $\mathrm{W}$ et al (2004). Prevalence and co-occurrence of substance use disorders and independent mood and anxiety disorders: results from the national epidemiologic survey on alcohol and related conditions. Arch Gen Psychiatry 61: 807-816.

Grant DA, Berg EA (1948). A behavioural analysis of degree of reinforcement and ease of shifting to new responses in a Weigltype card-sorting problem. J Exp Psychol 38: 404-411.

Grant S, Contoreggi C, London ED (2000). Drug abusers show impaired performance in a laboratory test of decision making. Neuropsychologia 38: 1180-1187.

Heller A, Bubula N, Lew R, Heller B, Won L (2001). Genderdependent enhanced adult neurotoxic response to methamphetamine following fetal exposure to the drug. J Pharmacol Exp Ther 298: 769-779.

Hester R, Garavan H (2004). Executive dysfunction in cocaine addiction: evidence for discordant frontal, cingulate, and cerebellar activity. J Neurosci 24: 11017-11022.

Hoff AL, Riordan H, Morris L, Cestaro V, Wieneke M, Alpert R et al (1996). Effects of crack cocaine on neurocognitive function. Psychiatry Res 60: 167-176.

Hornak J, O’Doherty J, Bramham J, Rolls ET, Morris RG, Bullock PR et al (2004). Reward-related reversal learning after surgical excisions in orbito-frontal or dorsolateral prefrontal cortex in humans. J Cogn Neurosci 16: 463-478.

Howell DC (1997). Statistical Methods for Psychology. Duxbury Press: London.

Hyman BT, Van Horsen GW, Damasio AR, Barnes CL (1984). Alzheimer's disease: cell-specific pathology isolates the hippocampal formation. Science 225: 1168-1170.

Joe GW, Dansereau DF, Pitre U, Simpson DD (1997). Effectiveness of node-link mapping enhanced counseling for opiate addicts: a 12-month posttreatment follow-up. J Nerv Mental Dis 185: 306-313.

Kaufman JN, Ross TJ, Stein EA, Garavan H (2003). Cingulate hypoactivity in cocaine users during a GO-NOGO task as revealed by event-related functional magnetic resonance imaging. J Neurosci 23: 7839-7843.

Kaufman MJ, Levin JM, Maas LC, Kukes TJ, Villafuerte RA, Dostal $\mathrm{K}$ et al (2001). Cocaine-induced cerebral vasoconstriction differs as a function of sex and menstrual cycle phase. Biol Psychiatry 49: 774-781.

Kim SJ, Lyoo IK, Hwang J, Sung YH, Lee HY, Lee DS et al (2005). Frontal glucose hypometabolism in abstinent methamphetamine users. Neuropsychopharmacology 30: 1383-1391.

King DE, Herning RI, Gorelick DA, Cadet JL (2000). Gender differences in the EEG of abstinent cocaine abusers. Neuropsychobiology 42: 93-98.

Kish SJ, Kalasinsky KS, Derkach P, Schmunk GA, Guttman M, Ang L et al (2001). Striatal dopaminergic and serotonergic markers in human heroin users. Neuropsychopharmacology 24: 561-567.

Leri F, Bruneau J, Stewart J (2003). Understanding polydrug use: review of heroin and cocaine co-use. Addiction 98: 7-22.

Levin JM, Holman BL, Mendelson JH, Siew Koon T, Garada B, Johnson KA et al (1994). Gender differences in cerebral perfusion in cocaine abuse: technetium-99m-HMPAO SPECT study of drug-abusing women. J Nucl Med 35: 1902-1909.

Lyoo IK, Streeter CC, Ahn KH, Lee HK, Pollack MH, Silveri MM et al (2004). White matter hyperintensities in subjects with cocaine and opiate dependence and healthy comparison subjects. Psychiatry Res: Neuroimag 131: 135-145.

Lyvers M, Yakimoff M (2003). Neuropsychological correlates of opioid dependence and withdrawal. Addict Behav 28: 605-611.
Maldonado R (1997). Participation of noradrenergic pathways in the expression of opiate withdrawal: biochemical and pharmacological evidence. Neurosci Biobehav Rev 21: 91-104.

Manes F, Sahakian BJ, Clark L, Rogers RD, Antoun N, Aitken M et al (2002). Decision-making processes following damage to the prefrontal cortex. Brain 125: 624-639.

Matochik JA, London ED, Eldreth DA, Cadet JL, Bolla KI (2003). Frontal cortical tissue composition in abstinent cocaine abusers: a magnetic resonance imaging study. Neuroimage 19: 1095-1102.

Medina KL, Shear PK, Schafer J, Amstrong TG, Dyer P (2004). Cognitive functioning and length of abstinence in polysubstance dependent men. Arch Clin Neuropsychol 19: 245-258.

Mehta MA, Sahakian BJ, McKenna PJ, Robbins TW (1999). Systemic sulpiride in young adult volunteers simulates the profile of cognitive deficits in Parkinson's disease. Psychopharmacology 146: 162-174.

Mintzer MZ, Stitzer ML (2002). Cognitive impairment in methadone maintenance patients. Drug Alcohol Depend 67: 41-51.

Murphy FC, Sahakian BJ, Rubinsztein JS, Michael A, Rogers RD, Robbins TW et al (1999). Emotional bias and inhibitory control processes in mania and depression. Psychol Med 29: 1307-1321.

Myers RE, Anderson LI, Dluzen DE (2003). Estrogen, but not testosterone, attenuates methamphetamine-evoked dopamine output from superfused striatal tissue of female and male mice. Neuropharmacology 44: 624-632.

Nelson DB, Kotranski L, Semaan S, Collier K, Lauby J, Feighan K et al (1998). The validity of self-reported opiate and cocaine use by out-of-treatment drug users. J Drug Issues 28: 483-494.

Nelson HE (1982). National Adult Reading Test Manual. NFERNelson: Windsor, UK.

Nestler EJ (2001). Neurobiology: total recall-the memory of addiction. Science 292: 2266-2267.

Nestler EJ (2002). Common molecular and cellular substrates of addiction and memory. Neurobiol Learn Memory 78: 637-647.

Newton TF, Kalechstein AD, Hardy DJ, Cook IA, Nestor L, Ling W et al (2004). Association between quantitative EEG and neurocognition in methamphetamine-dependent volunteers. Clin Neurophysiol 115: 194-198.

Nigg JT, Glass JM, Wong MM, Poon E, Jester JM, Fitzgerald HE et al (2004). Neuropsychological executive functioning in children at elevated risk for alcoholism: findings in early adolescence. J Abnormal Psychol 113: 302-314.

Ornstein TJ, Iddon JL, Baldacchino AM, Sahakian BJ, London M, Everitt BJ et al (2000). Profiles of cognitive dysfunction in chronic amphetamine and heroin abusers. Neuropsychopharmacology 23: 113-126.

Owen AM, Downes JJ, Sahakian BJ, Polkey CE, Robbins TW (1990). Planning and spatial working memory following frontallobe lesions in man. Neuropsychologia 28: 1021-1034.

Owen AM, James M, Leigh PN, Summers BA, Marsden CD, Quinn NP et al (1992). Fronto-striatal cognitive deficits at different stages of Parkinson's disease. Brain 115: 1727-1751.

Owen AM, Sahakian BJ, Hodges JR, Summers BA, Polkey CE, Robbins TW (1995a). Dopamine-dependent frontostriatal planning deficits in early parkinsons-disease. Neuropsychology 9: 126-140.

Owen AM, Sahakian BJ, Semple J, Polkey CE, Robbins TW (1995b). Visuo-spatial short-term recognition memory and learning after temporal lobe excisions, frontal lobe excisions or amygdalohippocampectomy in man. Neuropsychologia 33: 1-24.

Pantelis C, Barber FZ, Barnes TRE, Nelson HE, Owen AM, Robbins TW (1999). Comparison of set-shifting ability in patients with chronic schizophrenia and frontal lobe damage. Schizophrenia Research 37: 251-270.

Pantelis C, Barnes TR, Nelson HE, Tanner S, Weatherley L, Owen AM et al (1997). Frontal-striatal cognitive deficits in patients with chronic schizophrenia. Brain 120: 1823-1843. 
Pantelis C, Harvey CA, Plant G, Fossey E, Maruff P, Stuart GW et al (2004). Relationship of behavioural and symptomatic syndromes in schizophrenia to spatial working memory and attentional set-shifting ability. Psychol Med 34: 693-703.

Pantelis C, Yucel M, Wood SJ, McGorry PD, Velakoulis D (2003). Early and late neurodevelopmental disturbances in schizophrenia and their functional consequences. Austr NZ J Psychiatry 37: 399-406.

Parkinson JK, Murray EA, Mishkin M (1988). A selective mnemonic role for the hippocampus in monkeys-memory for the location of objects. J Neurosci 8: 4159-4167.

Pau CWH, Lee TMC, Chan SFF (2002). The impact of heroin on frontal executive functions. Arch Clin Neuropsychol 17: 663-670.

Paulus MP, Hozack NE, Zauscher BE, Frank L, Brown GG, Braff DL et al (2002). Behavioral and functional neuroimaging evidence for prefrontal dysfunction in methamphetamine-dependent subjects. Neuropsychopharmacology 26: 53-63.

Peel JL, Dansereau DF, Dees S (1996). Schematic maps: cognitive tools for enhancing the early stages of counseling. Am J Drug and Alcohol Abuse 22: 423-437.

Pezawas LM, Fischer G, Diamant K, Schneider C, Schindler SD, Thurnher $M$ et al (1998). Cerebral CT findings in male opioiddependent patients: stereological, planimetric and linear measurements. Psychiatry Res-Neuroimaging 83: 139-147.

Pitre U, Dansereau DF, Simpson DD (1997). The role of node-link maps in enhancing counseling efficiency. J Addict Dis 16: 39-49.

Porrino LJ, Beveridge T, Smith H, Nader M, Liguori A, Flowers L (2004). Imaging of cocaine self-administration in non-human primates can predict effects in human cocaine abusers. In: American College for Neuropsychopharmacology, 43rd Annual Meeting, San Juan, Puerto Rico.

Purcell R, Maruff P, Kyrios M, Pantelis C (1997). Neuropsychological function in young patients with unipolar major depression. Psychol Med 27: 1277-1285.

Robbins TW, Everitt J (2002). Limbic-striatal memory systems and drug addiction. Neurobiol Learn Memory 78: 625-636.

Robbins TW, Semple J, Kumar R, Truman MI, Shorter J, Ferraro A et al (1997). Effects of scopolamine on delayed-matching-tosample and paired associates tests of visual memory and learning in human subjects: comparison with diazepam and implications for dementia. Psychopharmacology 134: 95-106.

Robinson TE, Becker JB (1986). Enduring changes in brain and behavior produced by chronic amphetamine administration-a review and evaluation of animal-models of amphetamine psychosis. Brain Res Rev 11: 157-198.

Rogers RD, Andrews TC, Grasby PM, Brooks DJ, Robbins TW (2000). Contrasting cortical and subcortical activations produced by attentional-set shifting and reversal learning in humans. J Cogn Neurosci 12: 142-162.

Rogers RD, Blackshaw AJ, Middleton HC, Matthews K, Hawtin K, Crowley C et al (1999a). Tryptophan depletion impairs stimulusreward learning while methylphenidate disrupts attentional control in healthy young adults: implications for the monoaminergic basis of impulsive behaviour. Psychopharmacology 146: 482-491.

Rogers RD, Everitt BJ, Baldacchino A, Blackshaw AJ, Swainson R, Wynne $\mathrm{K}$ et al (1999b). Dissociable deficits in the decisionmaking cognition of chronic amphetamine abusers, opiate abusers, patients with focal damage to prefrontal cortex, and tryptophan-depleted normal volunteers: evidence for monoaminergic mechanisms. Neuropsychopharmacology 20: 322-339.

Rogers RD, Robbins TW (2001). Investigating the neurocognitive deficits associated with chronic drug misuse. Curr Opin Neurobiol 11: 250-257.
Rogers RD, Robbins TW (2003). The neuropsychology of chronic drug abuse. In: Ron MA, Robbins TW (eds). Disorders of Brain and Mind. Cambridge University Press: Cambridge.

Rotheram-Fuller E, Shoptaw S, Berman SM, London ED (2004). Impaired performance in a test of decision-making by opiatedependent tobacco smokers. Drug Alcohol Depend 73: 79-86.

Sahakian BJ, Morris RG, Evenden JL, Heald A, Levy R, Philpot M et al (1988). A comparative-study of visuospatial memory and learning in alzheimer-type dementia and parkinson's-disease. Brain 111: 695-718.

Seiden LS, Sabol KE, Ricaurte GA (1993). Amphetamine: effects on catecholamine systems and behavior. Annu Rev Pharmacol Toxicol 33: 639-676.

Simon SL, Domier CP, Sim T, Richardson K, Rawson RA, Ling W (2002). Cognitive performance of current methamphetamine and cocaine abusers. J Addict Dis 21: 61-74.

Specka M, Finkbeiner T, Lodemann E, Leifert K, Kluwig J, Gastpar M (2000). Cognitive-motor performance of methadone-maintained patients. Euro Addict Res 6: 8-19.

Stout JC, Rock SL, Campbell MC, Busemeyer JR, Finn PR (2005). Psychological processes underlying risky decisions in drug abusers. Addict Behav 19: 148-157.

Sweeney JA, Kmiec JA, Kupfer DJ (2000). Neuropsychologic impairments in bipolar and unipolar mood disorders on the CANTAB neurocognitive battery. Biological Psychiatry 48: 674-684.

Tarter RE, Kirisci L, Mezzich A, Cornelius JR, Pajer K, Vanyukov $\mathrm{M}$ et al (2003). Neurobehavioral disinhibition in childhood predicts early age at onset of substance use disorder. $A m \mathrm{~J}$ Psychiatry 160: 1078-1085.

Thompson PM, Hayashi KM, Simon SL, Geaga JA, Hong MS, Sui YH et al (2004). Structural abnormalities in the brains of human subjects who use methamphetamine. J Neurosci 24: 6028-6036.

UK Department of Health (1999). Drug Misuse and Dependence - Guidelines on Clinical Management. The Stationery Office Ltd: Norwich.

United Nations Office on Drugs and Crime (2003). Global Illicit Drug Trends 2003. United Nations Office on Drugs and Crime (UNODC): New York, NY.

Verdejo-Garcia A, Lopez-Torrecillas F, Gimenez CO, Perez-Garcia M (2004). Clinical implications and methodological challenges in the study of the neuropsychological correlates of cannabis, stimulant, and opioid abuse. Neuropsychol Rev 14: 1-41.

Verdejo-Garcia A, Toribio I, Orozco C, Puente KL, Perez-Garcia M (2005). Neuropsychological functioning in methadone maintenance patients $v s$ abstinent heroin abusers. Drug Alcoh Depend 78: $238-288$

Vorel SR, Liu X, Hayes RJ, Spector JA, Gardner EL (2001). Relapse to cocaine-seeking after hippocampal theta burst stimulation. Science 292: 1175-1178.

Wagner GC, Tekirian TL, Cheo CT (1993). Sexual differences in sensitivity to methamphetamine toxicity. J Neural Transm Gen Sect 93: 67-70.

Weiss EM, Kemmler G, Deisenhammer EA, Fleischhacker WW, Delazer M (2003). Sex differences in cognitive functions. Personality Individual Differences 35: 863-875.

Wilson JM, Kalasinsky KS, Levey AI, Bergeron C, Reiber G, Anthony RM et al (1996). Striatal dopamine nerve terminal markers in human, chronic methamphetamine users. Nat Med 2: 699-703.

Yu L, Liao PC (2000). Estrogen and progesterone distinctively modulate methamphetamine-induced dopamine and serotonin depletions in C57BL/6J mice. J Neur Transm 107: 1139-1147. 